\title{
Impact of methoprene on oogenesis of the freshwater crab Travancoriana schirnerae Bott, 1969 (Decapoda: Gecarcinucidae)
}

\section{Latha Nadkandi Padmanabhan, Sudha Devi Arath Raghavan* and Aswani Ayanath}

Department of Zoology and Research Centre, Mary Matha Arts and Science College, Mananthavady, Wayanad, Kerala, India 670 645.*Email: arsudhadevi@gmail.com.

\begin{abstract}
The current study investigated the impact of methoprene during different phases of oogenesis in the freshwater crab Travancoriana schirnerae Bott, 1969 (Decapoda: Gecarcinucidae), a non-target organism abundant in the wetlands of Wayanad, Kerala, India. Sublethal doses of methoprene impaired ovarian growth as evidenced by reduction in gonadosomatic values, fall in mean oocyte diameter and histopathological changes in all the phases of oogenesis. A significant drop in the proportion of mature oocytes in the experimental crabs were noticed, i.e. methoprene treatment delayed the growth of avitellogenic oocytes to previtellogenic and previtellogenic to early, middle or late vitellogenic stages. Reduction in proliferation of oogonia in the germinal zone and ruptured oolemma in chromatin nucleolus and perinuclear stage oocytes was persistent. Histopathological changes in the primary vitellogenic oocytes include karyoplasmic clumping, perinuclear space atresia, shrinkage and vacuolation of ooplasm, reduction in size of yolk globules and vacuolated globules and degeneration of follicle epithelium. Methoprene negatively affected yolk platelet formation as evidenced by the irregularly fused and distorted yolk platelets of late vitellogenic oocytes. The observed cellular deformities possibly suggest the direct effects of methoprene on the oocytes through general metabolism and growth or through hormones controlling ovarian growth.
\end{abstract}

Keywords: Histopathology; Karyoplasmic clumping; Karyorrhexis; Non-target organism; Oocytes.
Received

June 12, 2017

Accepted

June 28, 2017

Released

June 30, 2017

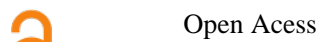

Full Text Article

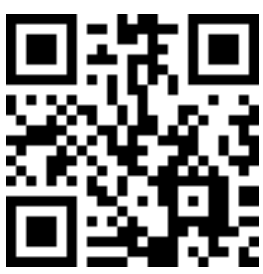

ORCID

(1) 0000-0002-7390-9659

Latha Nadkandi

Padmanabhan

(D) 0000-0003-4062-8073

Sudha Devi Arath

Raghavan

(D) 0000-0003-4184-6734

Aswani Ayanath

\section{Introduction}

Knowledge on the endocrine control of the complex larval developmental processes in insects has led to the introduction of insect hormones and their analogs as insecticides, known as insect growth regulators (IGRs). One of the most successfully used IGRs is methoprene, a growth regulating terpenoid, which manifests its toxicity on target insects by acting as an analog of the insect juvenile hormone $(\mathrm{JH})$ secreted by the corpora allata (Dale and Hulsman, 1990). Crustacean mandibular organ (MO) secretes a sesquiterpenoid hormone, methyl farnesoate (MF), the unepoxidated form of JH III (Laufer and Biggers, 2001) and methoprene mimics both JH and MF (De Fur et al., 1999). In association with the moulting hormone, JH suppresses adult differentiation to maintain immature 
characteristics of the developing insect (Wyatt and Davey, 1996) while MF regulates crustacean larval metamorphosis (Yamamoto et al., 1997) and stimulates reproduction (Homola and Chang, 1997). Methoprene enters wetlands either by direct application on aquatic pests or indirectly through land drainage or erosion from adjacent methoprene treated agricultural fields (Dhadialla et al., 1998).

Comprehensive studies have been conducted by several researchers on the impact of IGRs including methoprene on various aspects of oogenesis in insects (Gayathri and Muraleedharan, 2001; Fathpour et al., 2007). Studies show that compounds with $\mathrm{JH}$ activity which interrupt developmental processes in insects also affect crustaceans (Mu and Le Blanc, 2004). Changes induced by methoprene on larval survival (Celestial and McKenney, 1994), juvenile development (McKenney and Matthews, 1990), moult frequency, limb regeneration, growth rate (Olmstead and Le Blanc, 2001; Stueckle et al., 2009), adult mortality (Wirth et al., 2001), acute toxicity (Mortimer and Chapman, 1995), bioaccumulation, metabolic and morphologic effects (Walker et al., 2005; 2010) have received much attention.

From the available literature, it is clear that studies of methoprene impact on reproductive aspects of crustaceans are comparatively few; whatever reported is limited to microcrustaceans (Chu et al., 1997; Ghekiere et al., 2006). Very few studies have been devoted to the influence of methoprene on reproduction of macrocrustaceans. Topical application and ingestion of methoprene inhibited oogenesis in the estuarine mud crab Rhithropanopeus harrisii (Payen and Costlow, 1977). Hinsch (1981) observed the effects of $\mathrm{JH}$ mimics on the ovary of the immature spider crab Libinia emarginata. In Carcinus maenas, methoprene injection resulted in the enlargement of ovaries (Paulus and Laufer, 1982; Paulus, 1984). Reduced ovarian indices due to methoprene exposure were recorded in the Gulf sand fiddler crab Uca panacea (Tuberty, 2002).

The current study is an attempt to analyze the impact of methoprene application on different phases of oogenesis in an edible freshwater crab Travancoriana schirnerae, a non-target crustacean, commonly found on the embankments of rice fields, banana and areca plantations of Wayanad district, Kerala, India. Since freshwater crustaceans play a vital role in the trophodynamics of wetland/rice field ecosystems, it is important to assess the impact of methoprene on oogenesis of these ecologically fragile invertebrates

\section{Materials and methods}

\section{Test chemical}

Methoprene is a long chain hydrocarbon ester, characterized as an amber or pale yellow liquid with a faint fruity odour. The commercial product Diacon II containing $33.6 \%$ (S)methoprene/L as active ingredient (Wellmark International, IL, USA) was used as the source of methoprene in this study.

\section{Determination of $\mathrm{LD}_{50}$ for $\mathbf{4 8} \mathrm{h}$}

The acute toxicity study was carried out for a period of one year (March 2014-February 2015). Adult intermoult crabs (carapace width 4.0-5.0 cm) (body weight 20.47-45.83 g; 33.04 $\pm 6.27 \mathrm{~g}$ ) were collected from the paddy fields of Ondayangadi, about $5 \mathrm{~km}$ Northeast of Mananthavady $\left(11.82^{\circ} \mathrm{N}\right.$ and $76.02^{\circ} \mathrm{E}$, altitude $767 \mathrm{~m}$ ) in Wayanad District of Kerala. Fifty crabs were distributed into five groups of ten each. Group I, II, III, IV and $\mathrm{V}$ received injections of 50, 100, 150, 200 and $250 \mathrm{ppm}(\mathrm{mg} / \mathrm{L})$ (S)-methoprene, respectively. The crabs were kept separately in plastic tubs and observed for $48 \mathrm{~h}$. The mortality in each group was recorded. The $\mathrm{LD}_{50}$ (150 ppm for $48 \mathrm{~h}$ ) was determined using Probit analysis. One tenth of the $\mathrm{LD}_{50}(15 \mathrm{ppm})$ was used as the test dose in the present study.

\section{Experimental design}

Adult intermoult crabs were collected for a period of one year (March 2015-February 2016). The animals were acclimatized to laboratory conditions for three days. They were fed with boiled egg 
and pulses during the acclimation and experimental period. Every month, ten untreated crabs were maintained as controls and another ten as experimentals. To each experimental crab, $100 \mu \mathrm{L}$ of $15 \mathrm{ppm}$ (mg/L) (S)-methoprene was carefully injected into the body cavity through the arthrodial membrane of the third walking leg on days 1, 8, 15 and 22. A week after administration of the fourth dose, the animals were sacrificed. Ovaries from experimental and control animals were carefully dissected out; their size, colour and wet weights were recorded. The gonadosomatic index (GSI) was calculated using the formula: wet weight of gonad (g)/wet weight of whole body $(\mathrm{g}) \times 100$.

To characterize the vitellogenic stages, one half of the ovary was carefully torn open and diameters of 100 randomly choosen oocytes were recorded with a calibrated oculometer. The other half of the ovary was fixed in Bouin's solution for histological analysis. The tissues were dehydrated in graded series of ethanol and embedded in paraffin wax. Sections 5-6 $\mu \mathrm{m}$ thickness were stained with haematoxylineosin and examined under a Leica DM 500 Research Microscope. Measurements were recorded using an image analysis system of Biowizard software. Photomicrographs were taken with a DG 330/210 camera attached to the microscope. Student's t-test was applied in analyzing the data.

\section{Results}

The current investigation recorded the histopathological changes induced by methoprene treatment during different phases of oogenesis in T. schirnerae. The changes were assessed year round, focusing on GSI, morphological and histological features of the ovary.

Table 1. Changes in the oocyte diameter of T. schirnerae due to methoprene treatment.

\begin{tabular}{|l|c|c|c|c|}
\hline & \multicolumn{2}{|c|}{ Oocyte diameter $(\boldsymbol{\mu m})$} & \multicolumn{2}{c|}{ Nucleus diameter $(\boldsymbol{\mu m})$} \\
\hline Oocyte & Control & Treated & Control & Treated \\
\hline OO & $11.97 \pm 2.18$ & $8.57 \pm 1.59^{*}$ & $9.76 \pm 2.29$ & $6.65 \pm 1.80$ \\
\hline CN1 & $45.21 \pm 4.03$ & $38.98 \pm 2.59^{*}$ & $34.36 \pm 8.36$ & $24.30 \pm 7.31$ \\
\hline CN2 & $132.46 \pm 8.71$ & $119.04 \pm 11.29^{\#}$ & $46.05 \pm 9.70$ & $39.74 \pm 7.60$ \\
\hline CN3 & $244.98 \pm 2.52$ & $223.64 \pm 3.33^{*}$ & $51.81 \pm 10.09$ & $43.97 \pm 8.15$ \\
\hline PN & $384.44 \pm 11.89$ & $364.35 \pm 16.67^{* *}$ & $57.95 \pm 10.91$ & $50.58 \pm 10.78$ \\
\hline PV & $513.00 \pm 2.26$ & $479.35 \pm 2.72^{*}$ & $65.17 \pm 9.93$ & $55.52 \pm 9.09$ \\
\hline SV1 & $634.14 \pm 14.77$ & $579.61 \pm 42.65^{*}$ & $46.24 \pm 7.68$ & $38.10 \pm 7.42$ \\
\hline SV2 & $848.23 \pm 71.64$ & $787.92 \pm 67.49^{*}$ & $37.47 \pm 3.86$ & $30.97 \pm 6.82$ \\
\hline SV3 & $1103.72 \pm 16.72$ & $1024.5 \pm 74.35^{*}$ & $33.44 \pm 2.73$ & $25.42 \pm 3.20$ \\
\hline TV & $1352.43 \pm 81.13$ & $1283.31 \pm 6.21^{*}$ & -- & -- \\
\hline
\end{tabular}

The values are represented as Mean \pm S.D. ${ }^{*} p<0.01$, ${ }^{* *} p<0.05$, ${ }^{*}$ not significant.

\section{Histological changes in the ovary of crabs treated during the proliferation phase (April-May)}

The small, transparent and white proliferation phase ovaries of treated crabs appeared morphologically similar to that of the control crabs but exhibited significantly reduced GSI values (Figure 1A). The damage caused by methoprene treatment was evident from the reduced proliferation of oogonial cells as against clusters of oogonial cells seen in control crabs (Figures 1B, 2A and B). Pycnotic follicle nuclei, shrunken follicles and atretic oocytes were seen disbursed randomly. The chromatin nucleolus (CN) stage oocytes appeared elongate or deformed with indistinct borders, losing the typical round or oval configuration (Table 1). The difference observed in the mean oocyte diameter was not significant statistically $(p>0.05)$ (Table $2)$. Karyorrhexis, wherein the nuclear membrane and chromatin material found merging with the faintly basophilic and granular ooplasm leading to the dissolution of nucleus, was rampant in $\mathrm{CN}$ oocytes 


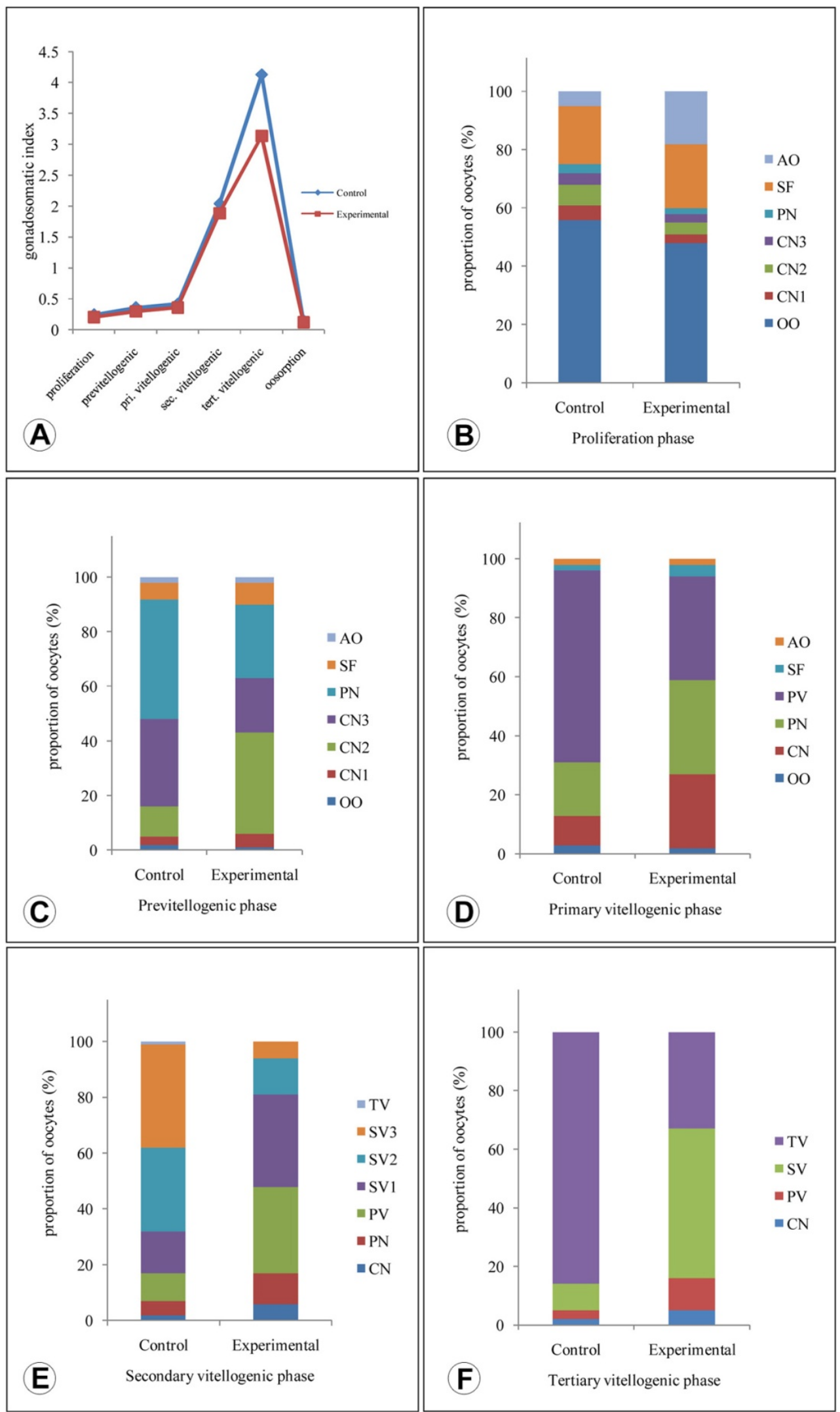

Figure 1. (A) Gonadosomatic index of control and treated T. schirnerae, (B-F) Proportion of oocytes in control and treated crabs during different phases of oogenesis. 
(Figure 2C). In some CN oocytes, ooplasm appeared granular and shrunken; retraction of chromatin content was more pronounced though intact nucleoli (1-5) were present. Moderate to extensive dissolution of ooplasmic contents were noticed (Figure 2D). These observations revealed that methoprene treatment during proliferation phase hampered normal ovarian growth leading to resorption of $\mathrm{CN}$ oocytes.

Table 2. Mean oocyte diameter of control and treated crabs during different phases of oogenesis.

\begin{tabular}{|l|c|c|}
\hline Phases of oogenesis & Control $(\boldsymbol{\mu m})$ & Experimental $(\boldsymbol{\mu m})$ \\
\hline Proliferation phase & $79.63 \pm 14.29$ & $72.56 \pm 9.26^{\#}$ \\
\hline Previtellogenic phase & $254.95 \pm 19.05$ & $208.18 \pm 13.44^{*}$ \\
\hline Primary vitellogenic phase & $412.69 \pm 15.08$ & $380.83 \pm 21.64^{*}$ \\
\hline Secondary vitellogenic phase & $831.56 \pm 31.12$ & $745.04 \pm 31.28^{*}$ \\
\hline Tertiary vitellogenic phase & $1097.18 \pm 31.03$ & $872.62 \pm 34.39^{* *}$ \\
\hline
\end{tabular}

The values are represented as Mean \pm S.D. ${ }^{*} p<0.05,{ }^{* *} p<0.01$, ${ }^{*}$ not significant.

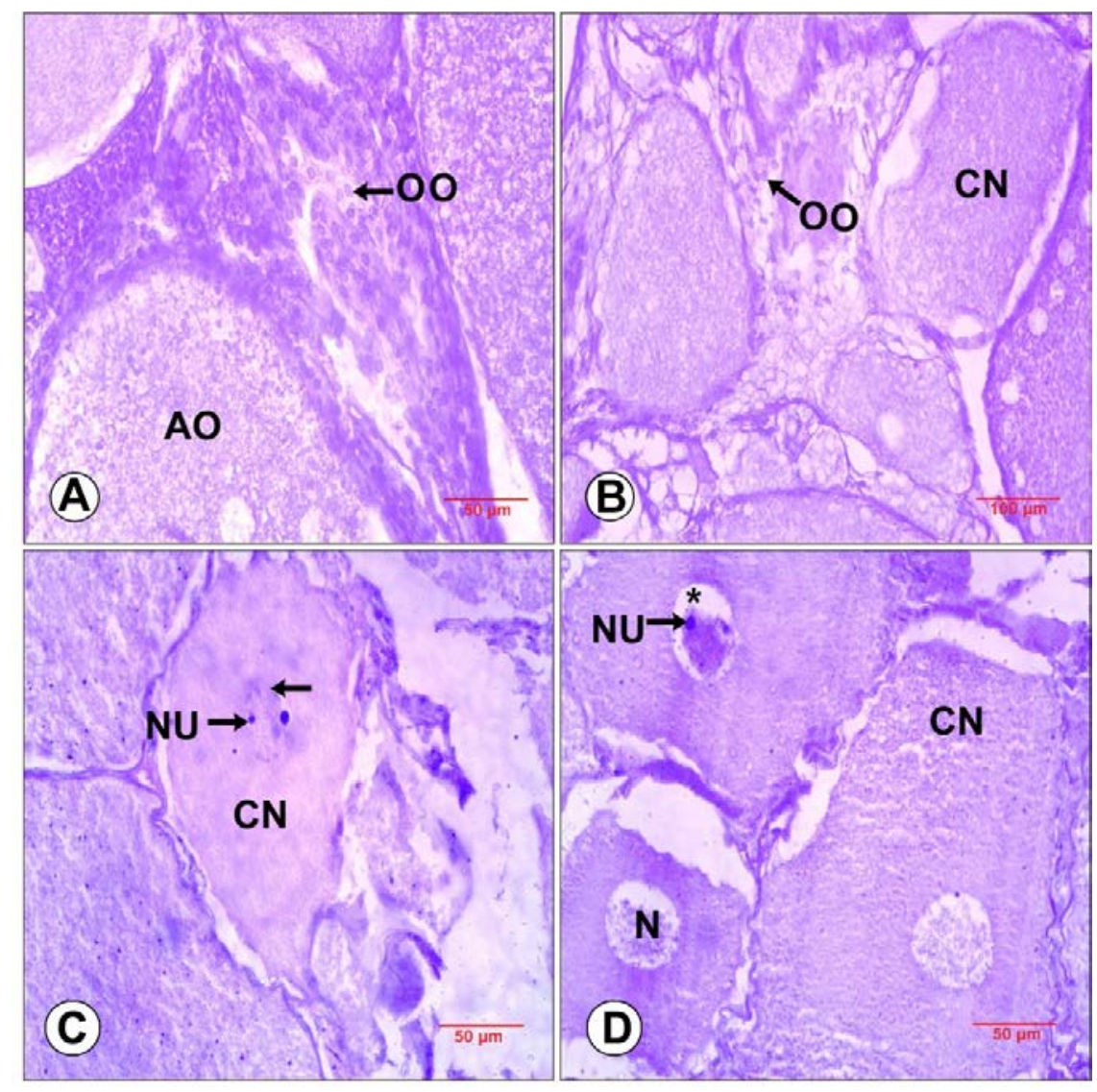

Figure 2. Histology of control and treated ovary in proliferation phase. (A) Ovary of control crab showing oogonial proliferation, (B) Reduced oogonial proliferation in treated females, (C-D) Deformed chromatin nucleolus stage I oocyte exhibiting karyorrhexis and ooplasmic retraction in ovary of treated crabs. AO: Atretic oocyte; CN: Chromatin nucleolus stage 1 oocyte; N: Nucleus; NU: Nucleolus; OO: Oogonium; Arrow indicates karyorrhexis; Asterix indicates retraction of chromatin. 


\section{Histopathology of ovary in previtellogenic phase (June-September)}

Macroscopically, no difference in the ovary was noticed in treated crabs of previtellogenic phase but their GSI was lower than the control group (Figure 1A). The ovaries of control crabs were opaque, with a creamish tinge and enclosed perinuclear (PN) and CN stage oocytes (Figure 1C). Vacuolated globules $(3.5-20.5 \mu \mathrm{m})$ were observed in the peripheral ooplasm of PN oocytes (Figure 3A). Experimental data showed that the mean oocyte diameter was found significantly different between control and experimental crabs (Table 2). Though CN2 oocytes were abundant, a decline in the number of $\mathrm{CN} 3$ and $\mathrm{PN}$ oocytes was noticed when compared to controls (Figures 1C). The reduction in the proportion of CN3 and PN oocytes indicate that further development of CN2 oocytes was hindered by methoprene treatment. The $\mathrm{CN} 1$ and
CN2 oocytes exhibited karyorrhexis while CN3 oocytes displayed karyoplasmic clumping, rupture of oolemma and retraction of ooplasm (Figure 3C).

The size of PN oocytes reduced considerably when compared to the controls (Table 1). In some PN oocytes, displacement and disorganization of nuclei was evident. The nuclear membrane appeared hazy, enclosing degenerated nucleoplasm with chromatin thickenings and nucleoli $(3.8-11.0 \mu \mathrm{m})$. Instances of oolemma merging with the follicle cells were also noticed. The ooplasmic changes due to methoprene injection include peripheral cytoplasmic shrinkage, perinuclear space atresia, vacuolations (6.4-13.6 $\mu \mathrm{m}$ diameter) and rupture of oolemma. Shrunken follicles, pycnotic follicle nuclei, empty spaces and debris were evident in the ovarian stroma of treated crabs (Figure 3B).

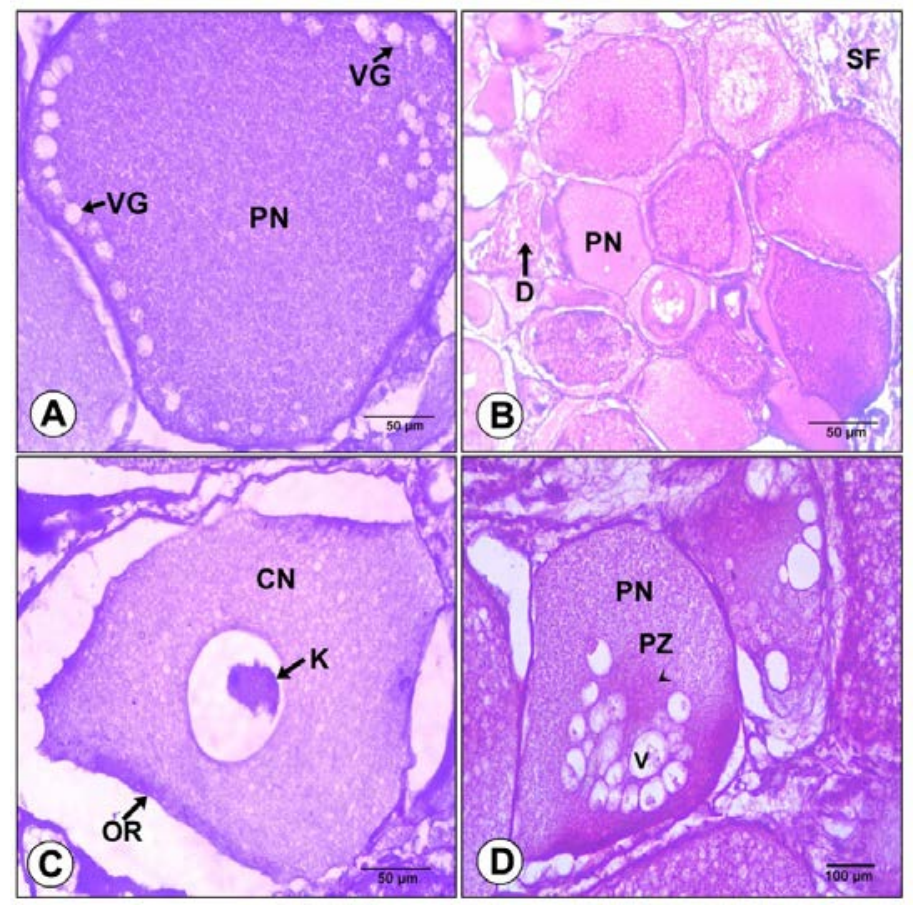

Figure 3. Impact of sublethal treatment of methoprene during previtellogenic phase. (A) Control ovary showing perinuclear stage oocyte, (B) Perinuclear stage oocyte exhibiting extensive vacuolations and degeneration, (C) Chromatin nucleolu stage oocyte undergoing karyoplasmic clumping and ooplasmic retraction, (D) Perinuclear space atresia and vacuolations in perinuclear oocytes. CN: Chromatin nucleolus stage oocyte; D: Debris; K: Karyoplasmic clumping; OR: Ooplasmic retraction; PN: 
Perinuclear stage oocyte; PZ: Perinuclear zone; SF: Shrunken follicle; V: Vacuolation; VG: Vacuolated globules; Arrow head indicates perinuclear space atresia.

\section{Histopathology of ovary in primary vitellogenic phase (October) \\ The ovaries of animals treated} during the primary vitellogenic phase did not show any visible morphological change. They exhibited light yellow colouration similar to that of controls but with appreciably decreased GSI values (Figure 1A). In control crabs, majority of the oocytes were in primary vitellogenic (PV) stage which showed the appearance of round, basophilic yolk globules (4.8-40 $\mu \mathrm{m})$ indicating the initiation of vitellogenesis (Figures 1D and 4A). Follicular epithelium (5.5-9.2 $\mu \mathrm{m})$ with many round to oval follicle cells (4.5-8.2 $\mu \mathrm{m})$ was also observed.

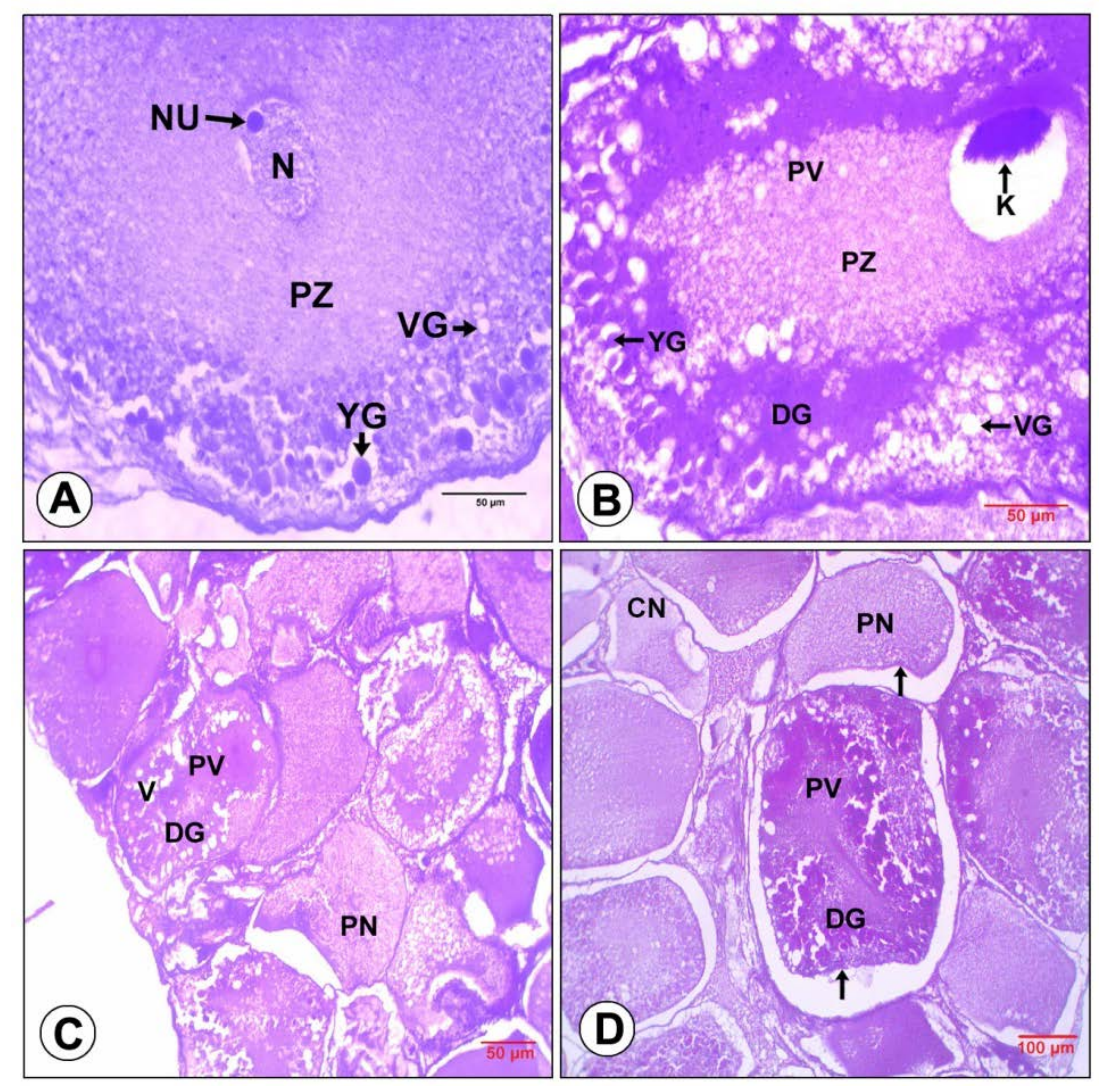

Figure 4. Histology of untreated and treated ovaries during primary vitellogenic phase. (A) Peripheral deposition of vacuolated globules and yolk globules in primary vitellogenic oocytes with wide perinuclear zone, (B) Primary vitellogenic oocyte exhibiting cytoplasmic retraction, karyoplasmic disintegration and degeneration of yolk globules, (C) Shrinkage of peripheral ooplasm and disintegrated yolk globules in perinuclear and primary vitellogenic oocytes, (D) Dissoluted perinuclear and cortical regions of perinuclear and primary vitellogenic oocytes. CN: Chromatin nucleolus stage; DG: Disintegrated yolk globules; K: Karyoplasmic clumping; N: Nucleus; NU: Nucleolus; PN: Perinuclear stage oocyte; PV: Primary vitellogenic oocyte; PZ: Perinuclear zone; V: Vacuolation; VG: Vacuolated globules; YG: Yolk globule.

Significant difference in the mean oocyte diameter was detected between the control and treated crabs $(p<0.05)$ (Table 2). Considerable reduction in the proportion of PV oocytes was noticed in the experimental crabs, an indication that methoprene treatment slowed down the progress of PN oocytes to PV stage (Figure 
1D). Oocytes in all stages exhibited cytoplasmic retraction and karyoplasmic disintegration.

A significant reduction in the diameter of PV oocytes was documented in all the treated crabs (Table 1). One or two prominent nucleoli $(3.8-11.8 \mu \mathrm{m})$ were observed in nuclei undergoing karyoplasmic clumping. The size of yolk globules $(1.6-14.0 \mu \mathrm{m})$ and vacuolated globules $\quad(6.5-11.2 \mu \mathrm{m})$ diminished substantially (Figure 4B). In the perinuclear and cortical regions of PN and PV oocytes, the ooplasm was seen dissoluted due to extensive vacuolations (3.8-14.0 $\mu \mathrm{m})$. Shrinkage of peripheral ooplasm and disintegration of yolk globules were apparent in PN and PV oocytes. The follicular epithelium around the PV oocytes appeared thin. Few shrunken follicles, empty spaces and debris were seen strewn among the PN and PV oocytes.

Histopathology of ovary in secondary vitellogenic phase (NovemberJanuary)

The ovaries of treated crabs appeared bright yellow, morphologically similar to control ovaries but with reduced GSI values (Figure 1A). The experimental crabs exhibited a significant decrease in mean oocyte diameter $(p<0.05)$ than their controls (Table 2). The percentage of secondary vitellogenic (SV) stage 2 oocytes diminished drastically against a considerable increase in the PV, SV1 and SV3 oocytes (Figure 1E).

In control crabs, the peripheral ooplasm of SV2 oocytes revealed large highly basophilic yolk globules (28.0-60.0 $\mu \mathrm{m})$ and vacuolated globules (18.0-40.0 $\mu \mathrm{m})$ advancing into the strongly basophilic perinuclear zone (Figures 5A-B). The SV3 oocytes attained maximum size and the polygonal, eosinophilic yolk platelets progressed further into the perinuclear space making the nuclei almost indistinguishable. Methoprene treatment induced a significant decrease in the size of SV oocytes when compared to the controls (Table 1). Their nuclei were indistinct, enclosing one or two intact nucleoli. In the perinuclear zone of SV2 oocytes, the yolk platelets appeared diffused unlike the control ovaries. The follicular epithelium surrounding SV1 and SV2 oocytes had a degenerated appearance in treated crabs. The uneven distribution of yolk globules and vacuolated globules interspersed with vacuolated areas in the ooplasm indicate disintegration of yolk deposition in SV3 oocytes (Figure 5C).

\section{Histopathology of ovary in tertiary vitellogenic phase (February- March)}

In control crabs, tertiary vitellogenic (TV) oocytes attained a maximum size with their nuclei becoming totally imperceptible. Eosinophilic yolk platelets occupied the peripheral ooplasm, forming a homogeneous matrix towards the centre (Figures 5D-E). Methoprene injection during this phase caused a significant reduction in GSI and mean oocyte diameter when compared to control crabs (Figure 1A, Table 2). Our observations revealed a considerable reduction in the proportion and diameter of TV oocytes with a substantial increase in the percentage of SV oocytes unlike the controls (Table 1, Figure 1F). Numerous empty spaces, distorted and irregularly fused yolk platelets indicated that TV oocytes were undergoing varying degrees of atresia (Figure 5F).

\section{Histopathology of ovary in oosorption phase (April)}

After spawning, the ovaries of control crabs appeared shrunken, acquiring a dirty white hue. The sagging ovarian stroma accommodated randomly distributed shrunken follicles and degenerating oogonia (Figure 6A). Methoprene induced histoanatomical variations were less pronounced in ovaries of this phase except a significant reduction in GSI value (Figure 1A). The sagging ovarian stroma accommodated randomly distributed shrunken follicles, degenerating oogonia and atretic vitellogenic oocytes (Figure 6B). 

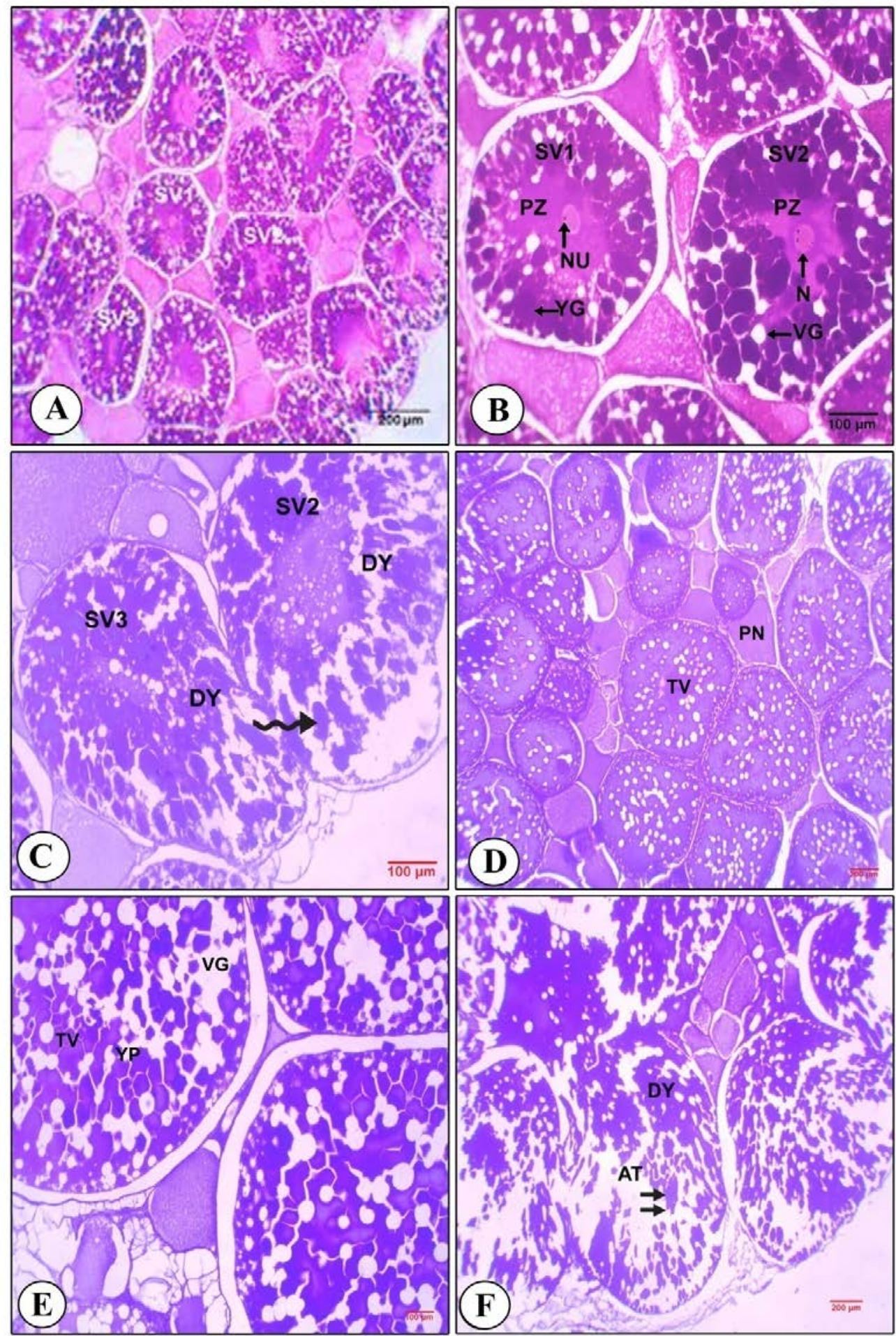

Figure 5. Histological features of ovary of control and treated crabs in secondary and tertiary vitellogenic phases. (A-B) Secondary vitellogenic phase ovary of control crabs, (C) Degenerated yolk globules and yolk platelets of SV2 and SV 3 oocytes, (D-E) Tertiary vitellogenic phase ovary of control crabs, (F) Atretic tertiary vitellogenic oocytes with irregularly fused yolk platelets. AT: Degenerating tertiary vitellogenic oocyte; DY: Degenerated yolk platelets; N: Nucleus; NU: Nucleolus; PN: Perinuclear stage oocyte; PZ: Perinuclear zone; SV1: Secondary vitellogenic stage 1 oocyte; SV2: Secondary vitellogenic stage 2 oocyte; SV3: Secondary vitellogenic stage 3 oocyte; TV: Tertiary vitellogenic oocyte; VG: Vacuolated globule; YG: Yolk globule; YP: Yolk platelet; Bent arrow indicates degenerated yolk globules; Double arrow indicates irregular fusion of yolk platelets. 

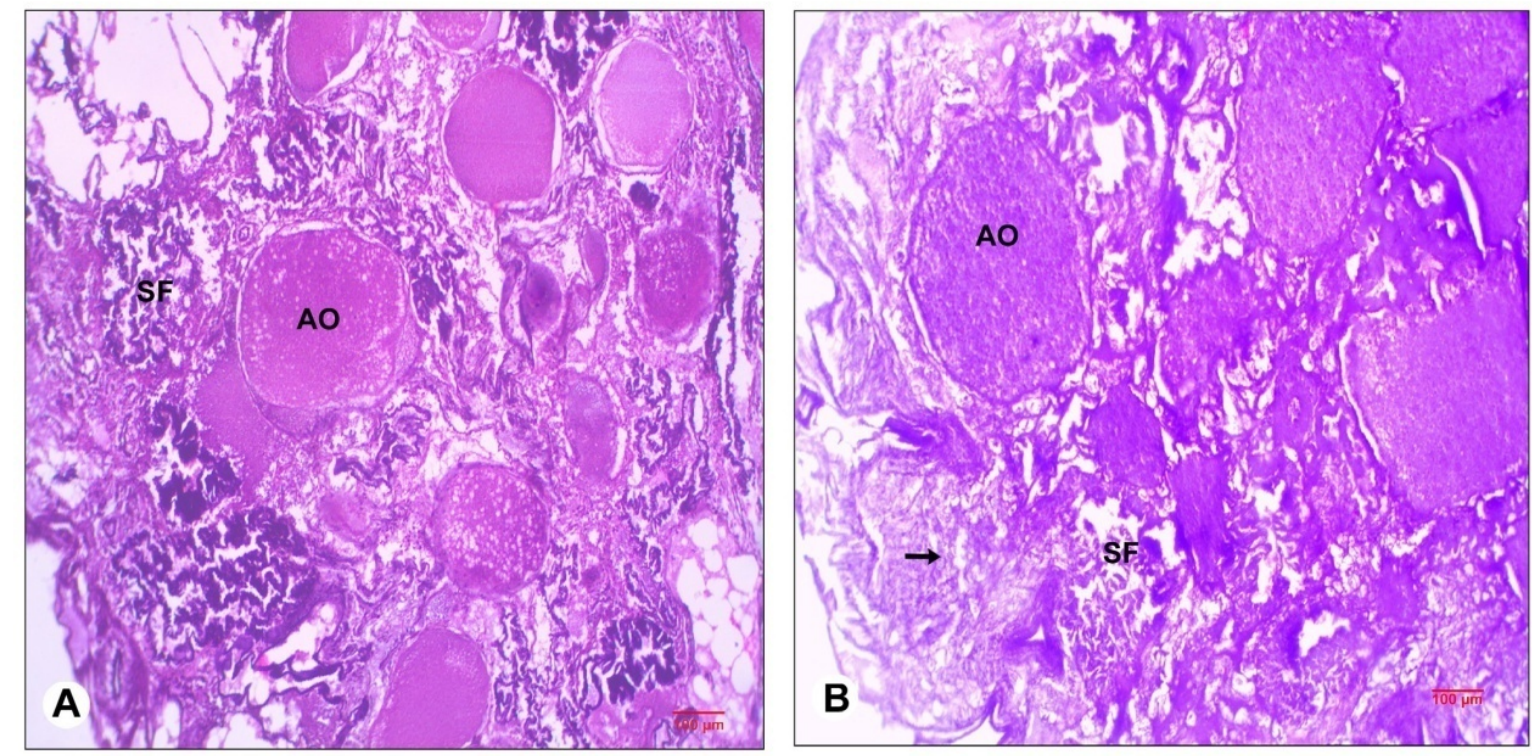

Figure 6. Histological features of ovaries of normal and methoprene treated crabs in oosorption phase. (A) Loosely dispersed ovarian stroma with numerous shrunken follicles, atretic oocytes and debris in control crabs, (B) Sagging ovarian stroma with shrunken follicles and atretic oocytes in treated crabs. AO: Atretic oocyte; SF: shrunken follicle; Arrow indicates cell debris.

\section{Discussion}

The current investigation clearly demonstrated that sublethal dose of methoprene impaired ovarian growth as evidenced by the reduction in GSI, diameter of oocytes and histopathological changes irrespective of the ovarian phases.

From the present study, it was obvious that methoprene treatment reduced the GSI values in all the phases of oogenesis. Gonadosomatic index is often used to assess gonad development and a reduced GSI points to a reduction in gonad mass or degeneration of gonads. Tuberty (2002) noticed a reduced GSI in $U$. panacea exposed to different doses of methoprene. In the crabs Chasmagnathus granulata, C. maenas and Geothelphusa dehaani, exposure to heavy metals demonstrated a dose dependent reduction in GSI values (Medesani et al., 2004; Elumalai et al., 2005; Yamaguchi et al., 2008). In the mud crab Scylla serrata, the GSI values exhibited a decreasing trend when exposed to sublethal concentrations of naphthalene irrespective of the vitellogenic phases (Vijayavel and
Balasubramanian, 2008). On the contrary, in the freshwater crayfish Procambarus clarkii fed with duckweeds containing cadmium significantly increased the ovarian index than the control groups fed with unpolluted duckweeds (Devi et al., 1996). No changes were noticed in GSI value due to sublethal exposure of endosulfan in the freshwater crab Zilchiopsis collastinensis (Negro, 2015).

Methoprene treatment significantly reduced oocyte growth as evidenced by a fall in the mean oocyte diameter in all the phases of oogenesis. Our findings were supported by the observations of Payen and Costlow (1977) and Rodriguez et al. (1994). Cadmium inhibited oocyte growth was reported in marine and freshwater decapods (Rodriguez et al., 2000; Padmanabhan and Mohan, 2013). In the freshwater prawn Macrobrachium rosenbergii, the diameter of previtellogenic and vitellogenic oocytes decreased with increase in tributyltin (TBT) concentration (Revathi et al., 2013). Conversely, chronic exposure to sublethal concentration of parathion caused a significant increase in the size of previtellogenic and vitellogenic 
oocytes in C. granulata (Rodriguez et al., 1994). In juveniles of this species, no difference in mean oocyte diameter was recorded between control and experimental crabs exposed to $0.1 \mathrm{mg} / \mathrm{L}$ of cadmium (Kogan et al., 2000). The fall in oocyte diameter may be attributed to the disruption of intra and extra-oocyte yolk synthesis by methoprene which in turn affects growth and metabolism of the developing oocytes.

In $T$. schirnerae, sublethal doses of methoprene retarded or slowed down the process of oogenesis/vitellogenesis as evidenced by a significant drop in the proportion of mature oocytes in the experimental crabs than their respective controls. Similar observations were recorded by Revathi et al. (2013) in $M$. rosenbergii, where TBT treated ovaries showed previtellogenic oocytes while control ovaries exhibited vitellogenic oocytes. By contrast, Kumar and Pant (1988) observed that the action of sublethal concentrations of organochlorine and organophosphate pesticides on oocytes of the freshwater fish Puntius conchonius was selective to specific oocyte stages.

The significant reduction in the proportion of mature oocytes in experimental crabs than their respective controls in the present study indicates that methoprene inhibits the release of growth stimulating hormone (GSH) from the neuroendocrine centres which in turn affects the levels of methyl farnesoate responsible for normal functioning of the ovary. Studies have shown that methoprene used in mosquito control adversely affected the reproductive performance of the estuarine mysid Mysidopsis bahia at very low concentrations through interference with the endogenous endocrine system (Pinder et al., 1999). In P. clarkii, naphthalene inhibited GSH release from neuroendocrine centres, resulting in atresia of the ovaries (Sarojini et al., 1994) and mercury inhibited the stimulatory effect of GSH on ovarian growth (Reddy et al., 1997). Fingerman et al. (1996) observed that the reproductive impairments caused by heavy metals were strongly related to imbalances in hormonal synthesis and/or secretions. Rodriguez et al. (2000; 2007) documented that heavy metals have shown to interfere with hormones that stimulate or inhibit gonadal growth.

The present study clearly demonstrated that methoprene treatment in the proliferation phase had significantly reduced the proliferation of oogonia from the germinal zone. Similar observations were reported by several researchers in decapods exposed to different pesticides (Dode et al., 2012; Watermann et al., 2013). On the other hand, in the copepod Acartia tonsa exposed to dichloro-diphenyl dichloroethylene, intensification of oogenesis with enhanced oogonial proliferation was documented by Watermann et al. (2011).

The results of the present study clearly indicated that methoprene treatment significantly affected the cytoarchitecture of previtellogenic oocytes. Similar results were obtained in $M$. kistensis treated with tributyltin chloride (Kharat et al., 2011) and cuprous oxide (Dode et al., 2012). Vacuolization, karyorrhexis and slow maturity was documented in C. granulata (Kogan et al., 2000) and Paratelphusa hydrodromous (Padmanabhan and Mohan, 2013) exposed to cadmium. The observed structural deformities in the previtellogenic oocytes of the current study may suggest methoprene-membrane interaction and the alteration of intercellular ionic composition.

In $T$. schirnerae methoprene induced an array of changes in the oocytes of primary vitellogenic phase ovary which include reduction in proportion and diameter of PV oocytes, shrinkage of peripheral ooplasm, karyoplasmic clumping, perinuclear space atresia, extensive vacuolations, reduced size of yolk globules and vacuolated globules. Similarly, reactional atresia and invasion of follicular cells (Kogan et al., 2000), degeneration of oocytes, membrane destruction and shrinkage of ooplasm (Shaikh et al., 2010), disorganization of nuclear region, peripheral cytoplasmic vacuolation and ruptured follicle epithelium (Dode et al., 2012), reduction in yolk globules, disruption of follicle cells and vacuolation of vitellogenic oocytes (Revathi et al., 2013) were recorded in 
decapods exposed to different concentrations of heavy metals and pesticides. The disorganization and degeneration of nucleus, perinuclear space atresia and ooplasmic vacuolations may have negative impact on intra-oocyte yolk synthesis (autosynthesis) which ultimately resulted in deformation of the oocytes.

In $T$. schirnerae, methoprene treatment negatively affected yolk platelet formation in late vitellogenic stages. Furthermore, methoprene treatment induced degeneration of the follicle epithelial layer which may have an impact on extra-ovarian yolk deposition of the vitellogenic oocytes. The sensitivity of follicular epithelium to methoprene is significant in the present study that follicle cells play an important role in incorporating yolk into the oocytes (heterosynthetic yolk deposition) as observed in several crustaceans (Yano and Chinzei, 1987; Yano, 1988). In the moth Cecropia, Anderson (1971) observed poor deposition of yolk in oocytes of pronase treated females. Endosulfan exposure resulted in the destruction of follicle cells of the freshwater crab Barytelphusa cunicularis (Jadhav and Shaikh, 2011). Large spaces between oocytes and follicle cells were observed in vitellogenic oocytes of juvenile L. emarginata treated with $\mathrm{JH}$ mimics (Hinsch, 1981). The degeneration of the follicle epithelium in the current study corroborates the earlier reports of several investigators on various pollutants.

\section{Conclusion}

The observed cellular deformities following methoprene exposure possibly suggest the direct effects of methoprene on the oocytes through general metabolism and growth or through hormones controlling ovarian growth.

\section{Acknowledgements}

This work was supported by Kannur University under the Junior Research Fellowship grant to the first author. The authors are thankful to Dr Paul G Fields, Cereal Research Centre,
Manitoba, Canada for the kind gift of Diacon II (methoprene).

\section{Conflict of interest statement}

The authors declare that they have no competing interests.

\section{References}

Anderson, L. Protein synthesis and uptake by isolated Cecropia oocytes. J. Cell. Sci., v. 8, p. 735-750, 1971. Available from: <http://jcs.biologists.org/content/joces/8/3/735.f ull.pdf>. Accessed on: Apr. 25, 2017.

Celestial, D. M.; McKenney, C. L. The influence of an insect growth regulator on the larval development of the mud crab Rhithropanopeus harrisii. Environ. Pollut., v. $85, \quad$ p. 169-173, 1994. https://doi.org/10.1016/0269-7491(94)90083-3

Chu, K. H.; Wong, C. K.; Chiu, K. C. Effects of the insect growth regulator (S) methoprene on survival and reproduction of the freshwater cladoceran Moina macrocopa. Environ. Pollut., v. 96, p. 173-178, 1997. https://doi.org/10.1016/S0269-7491(97)00030-4 Dale, P. E. R.; Hulsman, K. A critical review of salt marsh management methods for mosquito control. Rev. Aquat. Sci., v. 3, p. 281-311, 1990.

De Fur, P. L.; Crane, M.; Ingershold, C.; Tattersfield, L. Endocrine disruption in invertebrates: endocrinology, testing and assessment. Pensacola, Florida: Society of Environmental Toxicology and Chemistry, 1999.

Devi, M.; Thomas, D. A.; Barber, J. T.; Fingerman, M. Accumulation and physiological and biochemical effects of cadmium in a simple aquatic food chain. Ecotox. Environ. Safe., v. 33, p. 38-43, 1996.

Dhadialla, T. S.; Carlson, G. R.; Le, D. P. New insecticides with ecdysteroidal and juvenile hormone activity. Annu. Rev. Entomol., v. 43, p. 545-569, 1998.

Dode, C. R.; Chourpagar, A. R.; Dongre, S. B.; Nagabhushanam, R. Histological alteration in ovary of the freshwater prawn, Macrobrachium kistensis exposed to cuprous oxide. Elix. Aquacult., $\quad$ v. 53, p. 12086-12089, 2012. Available from: <http://www.elixirpublishers.com/articles/1355 750740_53\%20(2012)\%2012086-12089.pdf>. Accessed on: Apr. 25, 2017. 
Elumalai, M.; Antunes, C.; Guilhermino, L. Alterations of reproductive parameters in the crab Carcinus maenas after exposure to metals. Water, Air Soil Pollut., v. 160, p. 245-258, 2005. https://dx.doi.org/10.1007/s11270-0052992-9

Fathpour, H.; Noori, A.; Zeinali, B. Effects of a juvenoid pyriproxyfen on reproductive organ development and reproduction in German cockroach (Dictyoptera: Blattellidae). Iran. J. Sci. Technol., v. 31, p. 89-98, 2007. http://ijsts.shirazu.ac.ir/article2319408b055285f 0a9bc025530a961 3 dfdfa.pdf

Fingerman, M.; Devi, M.; Reddy, P. S.; Katyayani, R. Impact of heavy metal exposure on the nervous system and endocrine mediated processes in crustaceans. Zool. Stud., v. 35, p. 1-8, $1996 . \quad$ Available from: $<$ http://zoolstud.sinica.edu.tw/Journals/35.1/1.p df $>$. Accessed on: Apr. 25, 2017.

Gayathri, E. U.; Muraleedharan, D. Influence of juvenile hormone on the early embryonic development of Dysdercus cingulatus Fabr. (Heteroptera: Pyrrhocoridae). J. App. Entomol., v. 26, p. 173-182, 2001.

Ghekiere, A.; Verslycke, T.; Fockedey, N.; Janssen, C. R. Non-target effects of the insecticide methoprene on molting in the estuarine crustacean Neomysis integer (Crustacea: Mysidacea). J. Exp. Mar. Biol. Ecol., v. 332, p. 226-234, 2006.

Hinsch, G. W. Effects of juvenile hormone mimics on the ovary in the immature spider crab, Libinia emarginata. Int. J. Inver. Rep., v. 3, p. 237-244, 1981. http://dx.doi.org/10.1080/01651269.1981.10553 399

Homola, E.; Chang, E. S. Methyl farnesoate: crustacean juvenile hormone in search of functions. Comp. Biochem. Phys., v. 117B, p. 347-356, 1997.

Jadhav, T. J.; Shaikh, J. D. Histopathological changes in the ovary of freshwater crab (Barytelphusa cunicularis) exposed to endosulfan. DAV. Int. J. Sci., v. 1, p. 139-140, 2011.

Kharat, P. S.; Shejule, K. B.; Ghoble, B. C. Histopathological changes in ovary of freshwater prawn, Macrobrachium kistensis exposed to TBTCl. World J. Zool., v. 6, p. 296300, 2011.

Kogan, M.; Greco-Laura, L. S. L.; Romano, L. A.; Rodriguez, E. M. Effects of cadmium on somatic and gonadal growth of juvenile females of the estuarine crab, Chasmagnathus granulata
(Brachyura: Grapsidae). Zool. Stud., v. 39, p. 344-350, 2000. Available from: $<$ http://zoolstud.sinica.edu.tw/Journals/39.4/344 .pdf>. Accessed on: Apr. 25, 2017.

Kumar, S.; Pant, S. Comparative sublethal ovarian pathology of some pesticides in the teleost, Puntius conchonius Hamilton. B. Environ. Contam. Tox., v. 41, p. 227-232, 1988.

Laufer, H.; Biggers, W. J. Unifying concepts learned from methyl farnesoate for invertebrate reproduction and post-embryonic development. Am. Zool., v. 41, p. 442-457, 2001. https://dx.doi.org/10.1668/00031569(2001)041[0442:UCLFMF]2.0.CO;2

McKenney, C. L.; Mathews, E. Influence of an insect growth regulator on the larval development of an estuarine shrimp. Environ. Pollut., v. 64, p. 169-178, 1990.

Medesani, D. A.; Greco, L. S.; Rodriguez, M. Interference of cadmium and copper with the endocrine control of ovarian growth in the estuarine crab Chasmagnathus granulata. Aquat. Toxicol., v. 69, p. 165-174, 2004.

Mortimer, M. R.; Chapman, H. E. Acute toxic effects of (s)-methoprene and temephos to some Australian non-target aquatic crustacean species. Aust. J. Ecotox., v. 1, p. 107-111, 1995.

Mu, X. Y.; LeBlanc, G. A. Synergistic interaction of endocrine-disrupting chemicals: model development using an ecdysone receptor antagonist and a hormone synthesis inhibitor. Environ. Toxicol. Chem., v. 23, p. 1085-1091, 2004.

Negro, C. L. Histopathological effects of endosulfan to hepatopancreas, gills and ovary of the freshwater crab Zilchiopsis collastinensis (Decapoda: Trichodactylidae). Ecotox. Environ. Safe, v. 113, p. 87-94, 2015.

Olmstead, A. W.; Le Blanc, G. A. Low exposure concentration effects of methoprene on endocrine- regulated processes in the crustacean Daphnia magna. Toxicol. Sci., v. 62, p. 268-273, 2001.

Padmanabhan, A. M.; Mohan, K. Sublethal effects of cadmium on testicular and ovarian maturation in the freshwater crab Paratelphusa hydrodromous. Int. J. Pharm. Sci. Rev. Res., v. 23, p. 43-46, 2013.

Paulus, J. E. Hormonal control of vitellogenesis in decapod crustacean (Brachyura). University of Connecticut, 1984. (Thesis of Doctorate). 
Paulus, J. E.; Laufer, H. Vitellogenesis in the hepatopancreas and ovaries of Carcinus maenas. Biol. Bull., v. 163, p. 375-376, 1982.

Payen, G. G.; Costlow, J. D. Effects of a juvenile hormone mimic on male and female gametogenesis of the mud crab Rhithropanopeus harrisii (Gould) (Brachyura: Xanthidae). Biol. Bull., v. 152, p. 199-208, 1977.

Pinder, L. C. V.; Pottinger, T. G.; Billinghurst, Z.; Depledge, M. H. Endocrine function in aquatic invertebrates and evidence for disruption by environmental pollutants. Bristol: NERC Institute of Freshwater Ecology, Plymouth Environmental Research Centre, 1999. (R\&D Technical Report E67). <http://nora.nerc.ac.uk/7206/1/Endocrine_Funct ion_in_Aquatic_Invertebrates_and_Evidence_f or_Disruption_by_Environmental_Pollutants.pd f>. Accessed on: Nov. 16, 2016.

Reddy, P. S.; Tuberty, S. R.; Fingerman, M. Effects of cadmium and mercury on the ovarian maturation in the red swamp crayfish, Procambarus clarkii. Ecotox. Environ Safe, v. 37, p. 62-65, 1997.

Revathi, P.; Iyapparaj, P.; Arockia.; Vasanthi, L.; Munuswamy, N.; Krishnan, M.. Impact of TBT on the vitellogenesis and sex hormones in freshwater prawn Macrobrachium rosenbergii (De Man, 1879). Aquat, Biosys., v. 9, p. 10, 2013.

Rodriguez, E. M.; Lopez-Greco, L. S.; Fingerman, M. Inhibition of ovarian growth by cadmium in the fiddler crab Uca pugilator (Decapoda, Ocypodidae). Ecotox. Environ. Safe, v. 46, p. 202-206, 2000.

Rodriguez, E. M.; Schuldt, M.; Romano, L. Chronic histopathological effects of parathion and 2, 4-D on female gonads of Chasmagnathus granulate (Decapoda, Brachyura). Food. Chem. Toxicol., $\quad$ v. 32, p. 811-818, 1994. https://doi.org/10.1016/0278-6915(94)90157-0

Rodriguez, E. M.; Medesani, D. A.; Fingerman, M. Endocrine disruption in crustaceans due to pollutants: a review. Comp. Biochem. Phys., v. 146, p. 661-671, 2007.

Sarojini, R.; Nagabhushanam, R.; Fingerman, M. A possible neurotransmitter-neuroendocrine mechanism in naphthalene induced atresia of the ovary of the red swamp crayfish, Procambarus clarkii. Comp. Biochem. Phys., v. 108, p. 33-38. https://doi.org/10.1016/13678280(94)90085-X

Shaikh, F. I.; Ustad, I. R.; Ansari, N. T. Effect of mercuric chloride on the ovary of freshwater crab, Barytelphusa cunicularis. The Bioscan, v. 5, No. 2, p. 335-338, 2010. Available from: $<$ http://www.thebioscan.in/Journals_PDF/5236 F. I. Shaikh.pdf $>$. Accessed on: Nov. 16, 2016.

Stueckle, T. A.; Shock, B.; Foran, C. M. Multiple stressor effects of methoprene, permethrin and salinity on limb regeneration and molting in the mud fiddler crab (Uca pugnax). Environ. Toxicol. Chem., v. 28, p. 2348-2359, 2009.

Tuberty, S. R. Effects of the insect juvenile hormone agonist methoprene on female growth and reproduction in the Gulf sand fiddler crab, Uca panacea. Meeting of the Society of Integrative and Comparative Biology, Anaheim, California, 2-6 January 2002.

Vijayavel, K.; Balasubramanian, M. P. Changes in oxygen consumption and respiratory enzymes as stress indicators in an estuarine edible crab Scylla serrata exposed to naphthalene. Chemosphere, v. 63, p. 1523-1531, 2008.

Walker, A. N.; Bush, P.; Puritz, J.; Wilson, T.; Chang, E. S.; Miller, Y.; Holloway, K.; Horst, M. N. Bioaccumulation and metabolic effects of the endocrine disruptor methoprene in the lobster, Homarus americanus. Integr. Comp. Biol., v. 45, p. 118-126, 2005. https://dx.doi.org/ 10.1093/icb/45.1.118

Walker, A. N.; Golden, R.; Horst, M. N. Morphologic effects of in vivo acute exposure to the pesticide methoprene on the hepatopancreas of a non-target organism, Homarus americanus. Ecotox. Environ. Safe, v. 73, p. 1867-1874, 2010.

Watermann, B. T.; Albanis, T. A.; Dagnac, T.; Gnass, K.; Kusk, K. O.; Sakkas, V. A.; Wollenberger, L. Effects of methyl-testosterone, letrozole, triphenyltin and fenarimol on histology of reproductive organs of the copepod Acartia tonsa. Chemosphere, v. 92, p. 544-554, 2013.

Watermann, B. T.; Gnass, K.; Kolodzey, H.; Thomsen, A. E. Laboratory tests with androgenic and anti-androgenic pesticides: comparative studies on endocrine modulation in the reproductive system of invertebrates and vertebrates. In: Stoytcheva, M. (Ed.). Pesticides in the Modern World: effects of pesticides exposure. Shanghai: In Tech, 2011.

Wirth, E. F.; Lund, S. A.; Fulton, M. H.; Scott, G. I. Determination of acute mortality in adults and sublethal embryo responses of Palaemonetes pugio to endosulfan and methoprene exposure. Aquat. Toxicol., v. 53, p. 9-18, 2001.

Wyatt, G. R.; Davey, K. G. Cellular and molecular actions of juvenile hormone. II. Roles 
of juvenile hormone in adult insects. Adv. Insect. Physiol., v. 26, p. 1-155, 1996.

Yamaguchi, S.; Celino, F. T.; Ito, A.; Agusa, T.; Tanabe, S.; Bui.; Cach, T.; Miura, C.; Miura, T. Effects of arsenic on gonadal development in freshwater crab, Somanniathelphusa pax in Vietnam and Geothelphusa dehaani in Japan. Ecotoxicology, v. 17, p. 772-780, 2008.

Yamamoto, H.; Okino, T.; Yoshimura, E.; Tachibana, A.; Shimizu, K.; Fusetani, N. Methyl farnesoate induces larval metamorphosis of the barnacle, Balanus amphitrite via protein kinase C activation. J. Exp. Zool., v. 278, p. 349-355, 1997.

Yano, I. Oocyte development in the kuruma prawn Penaeus japonicus. Mar. Biol., v. 99, p. 547-553, 1988.

Yano, I.; Chinzei, Y. Ovary is the site of vitellogenin synthesis in kuruma prawn, Penaeus japonicus. Comp. Biochem. Phys., v. 86, p. 213-218, 1987.

License information: This is an open-access article distributed under the terms of the Creative Commons Attribution License, which permits unrestricted use, distribution, and reproduction in any medium, provided the original work is properly cited. 